\title{
Monitoring the biomass content in the aerobic digestor of a WWTP: correlation between gravimetric and optical methods
}

\author{
M. Salaverría ${ }^{1}$, A. Elías ${ }^{1}$, A. Iturriarte ${ }^{2}$, L. Gurtubay ${ }^{1}$ \& S. Paunero ${ }^{2}$ \\ ${ }^{I}$ Department of Chemical and Environmental Engineering, \\ University of the Basque Country, Spain \\ ${ }^{2}$ Operational Department, Acciona Agua Bilbao, Vizcaya, Spain
}

\begin{abstract}
The aim of this work is to develop reliable and quick methods to quantify the amount of active biomass in the aerobic reactor of a Wastewater Treatment Plant (WWTP). The removal of pollutants contained in wastewaters is carried out by several processes involving physical, chemical and biological treatments. The biological treatment renders the elimination of the organic matter and takes place in aerobic reactors. A constant concentration of microorganisms in the reactor system ensures a high degradation performance, since an inappropriate biomass amount would hinder the process efficiency. Although the most used method to control microorganisms' growth is based on the measurement of the solids content in the mixture, this simple determination has several drawbacks. First, it is a tedious procedure, which requires more than $24 \mathrm{~h}$-performance, delaying the decision-making and proper control of the sludge recirculation rate. The second disadvantage is the lack of a standardized method for result calculation. Finally, high solids content is not directly related to a big amount of active biomass. In this study, absorbance and turbidity have been selected as additional parameters in order to obtain a reliable correlation between those optical parameters and dry weight measures. A quick measurement of absorbance or turbidity, related to the quantity of solids in the sample, makes the decision-making easier in the everyday operation of the plant.
\end{abstract}

Keywords: WWTP, biomass, solids content, absorbance, turbidity, correlation. 


\section{Introduction}

Wastewater Treatment Plants (WWTP) are necessary to reduce the contaminants contained in sewage, before water returns to the environment. The biological reactor is the stage in which organic matter degrades, due to the activity of the microorganisms contained in the sludge. Most plants operate in aerobic conditions, recycling part of the sludge to maintain the level of microorganisms in the vessel and removing their excess. The aeration tank volume of the plant selected in this study is $860 \mathrm{~m}^{3}$. There, bacteria and protozoa from the activated sludge are fed by pollutants and consequently pollutants are degraded. The key parameter to control that process is the viable biomass, which is troublesome to measure. There have been several proposals to seek an indicator which provides a good measure of the active biomass, such as gravimetric, optical or electrical methods.

One of the most used parameter is the solids content. However, whereas some authors [1] determine Volatile Suspended Solids (VSS), others [2, 3] use Total Suspended Solids (TSS). Methods based on solids content appear to be a good alternative, but they are not immediate and they are not directly associated with viable biomass.

Absorbance can also be a good indicator of microbial growth, although there is no agreement about the most appropriate wavelength. Thus, Muñoz et al. [4], selected $650 \mathrm{~nm}$, Jiang et al. [5], used $480 \mathrm{~nm}$. Other optical method which can be applied is turbidity, employed by van Benthem and de Grave [6]. Optical methods have the advantage of their immediacy, but interferences can be significant.

Other methods, based on respirometric procedures, may also be suitable for the determination of microbial activity. Oxygen Uptake Rate (OUR) is frequently used [7]. The great advantage of these methods is that they are directly linked to the biological activity of the sludge. However, respirometric rate changes with the age of the sludge, so an exhaustive knowledge of the state of the biocenosis is required.

Finally, studies concerning microbiological procedures could give very detailed information about the sludge. But these processes are complex and costly.

This study has been carried out to compare different parameters used to control the viable biomass in activated sludge. Since all the methods present advantages and disadvantages, we have used some of them to assess the best one as far as time, simplicity and accuracy are concerned.

\section{Materials and methods}

\subsection{Sampling}

Activated sludge was sampled from January to May 2010 in the aeration tank of the WWTP in Muskiz (Spain). The samples were taken with a bucket from 6 different points of the tank, and collected in 2-L, polyethylene bottles. They 


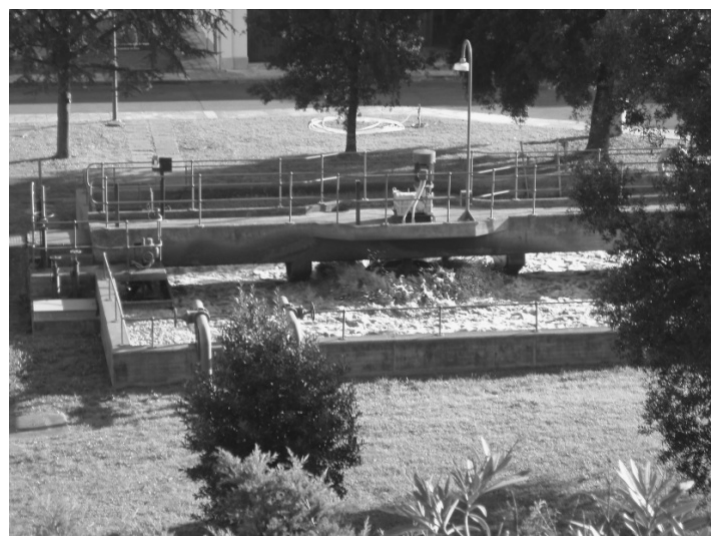

Figure 1: $\quad$ Aeration tank in Muskiz.

were kept refrigerated during transport to the laboratory, and analysis was made immediately, never exceeding $24 \mathrm{~h}$ [8].

\subsection{Conductivity, $\mathrm{pH}$ and temperature}

These three factors were considered as control parameters to verify the correct running of the plant. Conductivity, $\mathrm{pH}$ and temperature were measured, just after the sampling, with a Thermo Scientific Orion 4-Star Plus portable meter.

\subsection{Settleable solids}

Settleable solids were measured according to the Standard Methods for the Examination of Water and Wastewater [8] and following the volumetric procedure. The procedure involved filling an Imhoff cone with $1 \mathrm{~L}$ of mixed sample. The volume of settleable solids in the cone was recorded after $1 \mathrm{~h}$.

\subsection{Biomass estimation}

\subsubsection{Solids content}

Solids content include suspended or dissolved matter in the mixed liquor. The determination of Total Solids (TS) was carried out by sampling $50 \mathrm{~mL}$ of mixed liquor and evaporating in an oven at $105^{\circ} \mathrm{C}$ during $24 \mathrm{~h}$. Volatile Solids (VS) were determined by heating the residue at $550^{\circ} \mathrm{C}$ in a muffle during $1 \mathrm{~h}$,.

The Whatman $G F / C$ filters used for the measurement of Total Suspended Solids (TSS) were washed with three successive $20-\mathrm{mL}$ portions of deionised water, and ignited at $550^{\circ} \mathrm{C}$, for $15 \mathrm{~min}$, before use. For the determination of TSS, a $100-\mathrm{mL}$ sample was filtered and the filter was dried at $105^{\circ} \mathrm{C}$, during $1 \mathrm{~h}$. Finally, the weigh loss after ignition at $550^{\circ} \mathrm{C}$ during $1 \mathrm{~h}$, was the Volatile Suspended Solids (VSS). 
Total Dissolved Solids (TDS) and Volatile Dissolved Solids (VDS) were measured following the same procedure of the TS and VS, but taking a sample from the filtered liquid.

\subsubsection{Absorbance}

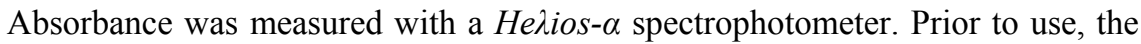
device was equilibrated, and the baseline was adjusted with a glass cell full of deionised water. Next, the cell was filled with original sample. Since the solids content was high, and they settled fast, the sample was carefully homogenized by magnetic stirring before filling the cell. Absorbance was determined at 400, 500 and $600 \mathrm{~nm}$.

\subsection{Turbidity}

Turbidity of the mixed liquor was quantified with a $H A C H$ 2100-P turbidimeter. Two calibration standard solutions of 10.0 and 500 NTU were used. After the calibration, each sample was introduced in the cell to measure the turbidity.

\subsection{Experimental design}

\subsubsection{Calibration curve}

In order to correlate the gravimetric and optical results the original mixed liquor was previously mixed with deionised water at different dilution ratios. Mixtures with a $0: 10,1: 9,2: 8,3: 7,4: 6,5: 5,6: 4,7: 3,8: 2,9: 1$ and 10:0 (v/v) ratio were prepared. The absorbance and turbidity of each solution was measured and results are shown in figure 2 . In order to achieve a high correlation coefficient, the last three points of each curve were not considered.

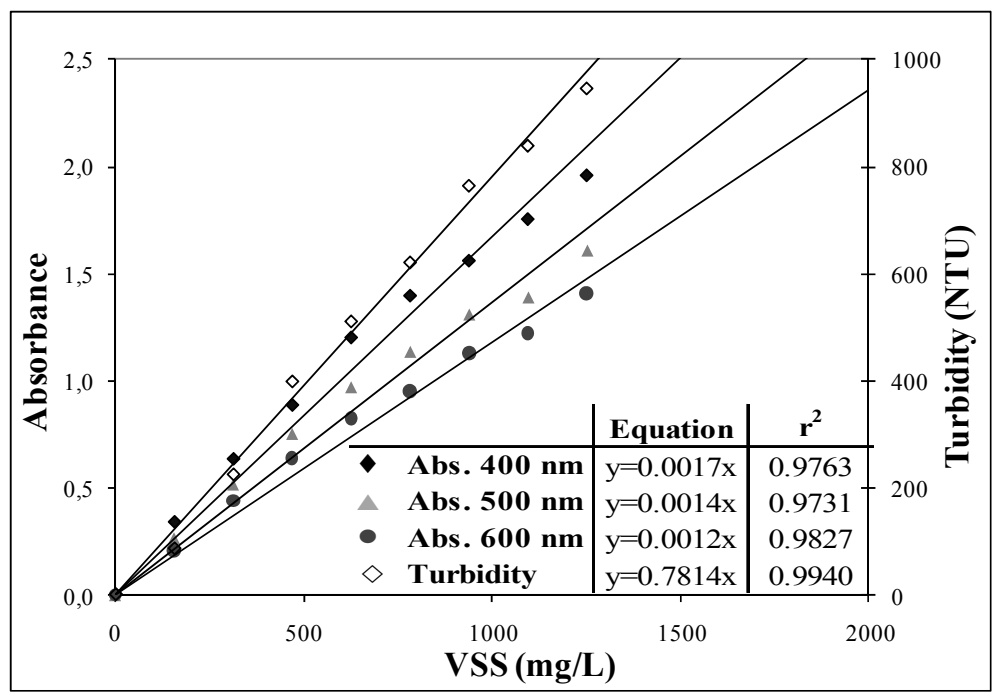

Figure 2: Calibration curve between VSS and optical parameters. 
As shown in figure 2, gravimetrical and optical methods correlated well. Nevertheless, if the sample has a high VSS content, dilution of the sample until VSS values lower than $1500 \mathrm{mg} / \mathrm{L}$ is recommended before measuring the absorbance or turbidity. Thus, the experimental results will be within the studied range and within the best fit.

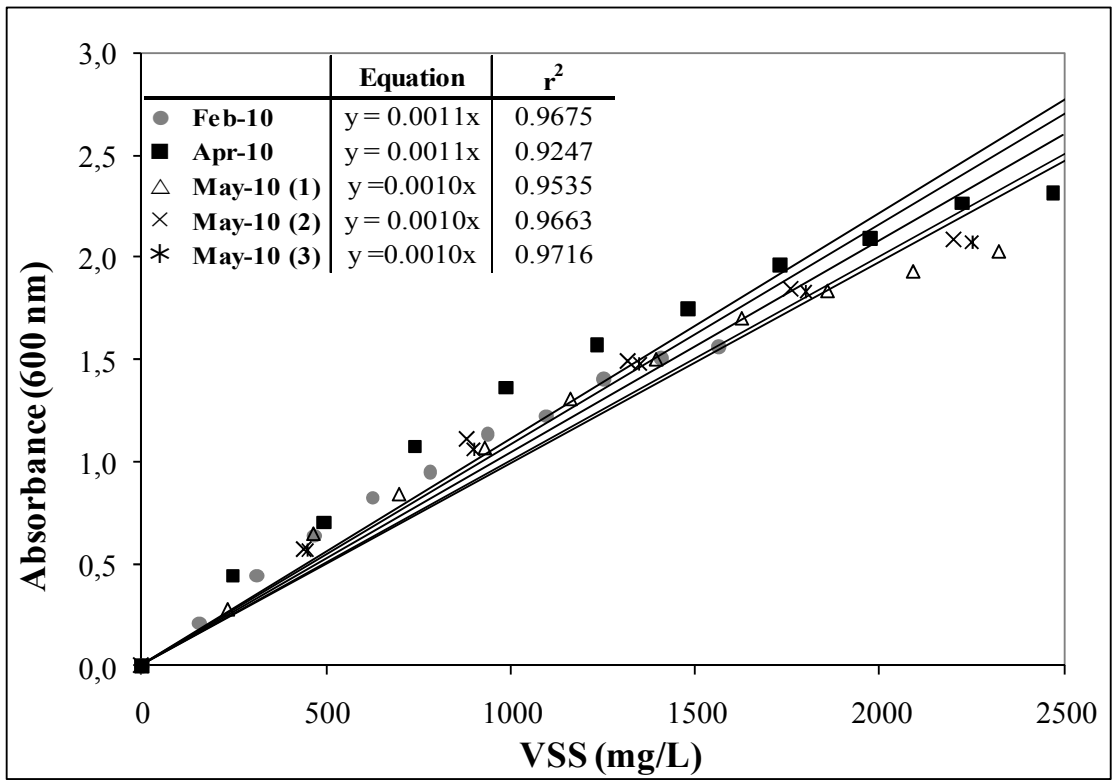

Figure 3: Calibration curves between VSS and Absorbance at $600 \mathrm{~nm}$.

As shown in figure 3, calibration curves with samples collected at different dates showed similar equations. The absorbance results of samples collected during consecutive months revealed that the ratio between this parameter and the VSS content remained constant.

\section{Results}

The control of the "quality" of the incoming wastewater, in terms of $\mathrm{pH}$, conductivity and solids content, is compulsory.

The sewage $\mathrm{pH}$ and conductivity values throughout 8 months of operation are represented in Figure 4 (data provided by the operators at the WWTP in Muskiz). The $\mathrm{pH}$ values ranged between 7.1 and 7.8. However, in some unexpected moments (November, February and April), certain values were out of this range, probably due to sporadic industrial spilling or sea-water intrusion episodes. During, those episodes, high conductivity values (up to $1500 \mu \mathrm{S} / \mathrm{cm}$ ) were also recorded. Conductivity values usually ranged from 500 to $1000 \mu \mathrm{S} / \mathrm{cm}$ during regular operation. 


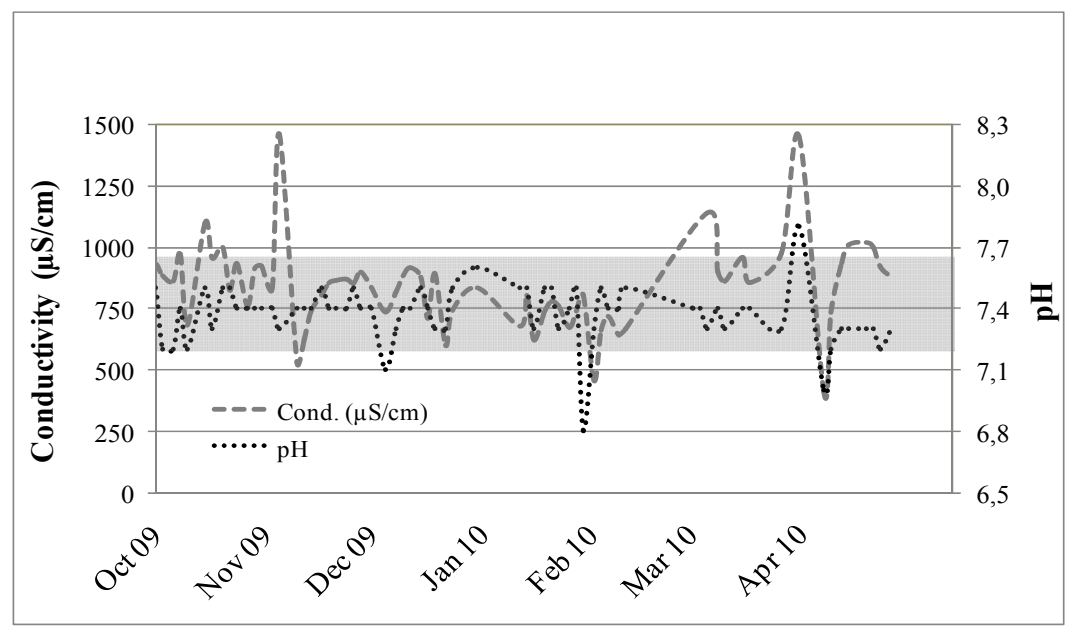

Figure 4: Evolution of incoming sewage $\mathrm{pH}$ and conductivity.

During the project, several samples were taken and experimental work was carried out once a week. The results obtained in different sampling points, as well as in different operations times, were very similar. According by, and in order to avoid repetitivity some of the results have been omitted and the average representative value for each month has been shown.

The results of the solids content from January to May are shown in Table 1.

Table 1: $\quad$ Solids content average in the mixed liquor.

\begin{tabular}{ccccc}
\hline & TS (g/L) & VS/TS & VSS (g/L) & VSS/TS \\
\hline Jan-10 & 2.43 & 0.62 & 1.56 & 0.64 \\
\hline Feb-10 & 2.42 & 0.64 & 1.56 & 0.64 \\
\hline Mar-10 & 2.90 & 0.69 & 1.85 & 0.64 \\
\hline Apr-10 & 3.99 & 0.73 & 2.47 & 0.62 \\
\hline May-10 & 3.19 & 0.71 & 2.26 & 0.71 \\
\hline
\end{tabular}

The TS values were constant for the first months. Nevertheless, these values were higher during the last sampling months due to the increase in the sludge recirculation rate in the aerobic step.

During this period of time, calibration curves were obtained to correlate the absorbance and turbidity with the solids content. The criterion followed to validate calibration curves was that VSS values obtained by gravimetrical methods differed less than $10 \%$ from those calculated from the correlation curve, obtained by optical parameters.

\section{Conclusions}

The following conclusions were obtained: 
- Optical methods, such as turbidity and absorbance, are highly recommended as reliable and fast alternatives to measure the VSS content in wastewater.

- The selection of a high wavelength is recommended to minimize the interference generated by the TDS.

- When the sample has a high VSS content, dilution until VSS values lower than $1500 \mathrm{mg} / \mathrm{L}$ is advisable before measuring the optical parameters.

- The absorbance results of samples collected during consecutive months revealed that the ratio between this parameter and the VSS content remained constant.

Nevertheless, further research about microbiological parameters is required. Consequently, in order to reach a better knowledge of the viability of the biomass in the aeration tank, we are currently conducting a further study about the microbiological state of the biomass.

\section{Acknowledgements}

The authors acknowledge the University of the Basque Country (Research group GIU08/10UPV) for the financial support for the project. We also thank Consorcio de Aguas de Bizkaia, and especially Alicia Iturriarte (Acciona) for providing samples and historical data from the WWTP of Muskiz.

\section{References}

[1] Farabegoli, G., Chiavola, A. \& Rolle, E., The Biological Aerated Filter (BAF) as alternative treatment for domestic sewage. Optimization of plant performance. Journal of Hazardous Materials, 171, pp. 1126-1132, 2009.

[2] Lu, Z., Zhang, M., Hua, L., Wang, R. \& Wu, G., Treatment and recirculation technology of paper mill waste water. Appita Journal, 62, pp. 339-342, 2009.

[3] Pabón, S.L. \& Suárez Gélvez, J.H., Arranque y operación a escala real de un sistema de tratamiento de lodos activos para aguas residuales de matadero. Ingeniería e Investigación, 29, pp. 53-58, 2009.

[4] Muñoz, R., Díaz, L.F., Bordel, S. \& Villaverde, S., Response of Pseudomonas putida $\mathrm{Fl}$ cultures to fluctuating toluene loads and operational failures in suspended growth bioreactors. Biodegradation, 19, pp. 897-908, 2008.

[5] Jiang, R., Huang, S., Chow, A.T. \& Yang, J., Nitric oxide removal from flue gas with a biotrickling filter using Pseudomonas putida. Journal of Hazardous Materials, 164, pp. 432-441, 2009.

[6] van Benthem, R. \& de Grave, W., Turbidity sensor for bacterial growth measurements in spaceflight and simulated micro-gravity. Microgravity Science and Technology, 21, pp. 349-356, 2009. 
[7] Moussa, M.S., Hooijmans, C.M., Lubberding, H.J., Gijzen, H.J. \& van Loosdrecht, M.C.M., Modelling nitrification, heterotrophic growth and predation in activated sludge. Water Research, 39, pp. 5080-5098, 2005.

[8] APHA-AWWA-WEF, Standard Methods for the Examination of Water and Wastewater ( $21^{\text {st }}$ edition). Washington, 2005. 